\title{
COMPARISON OF EMPIRICAL FORCE FIELDS FOR BACTERIOCHLOROPHYLL: AN INFLUENCE ON HYDRATION AND LONG-TIME DYNAMICS OF BACTERIAL PHOTOREACTION CENTERS
}

\begin{abstract}
The choice of an adequate empirical force field for photosynthetic cofactors is the major prerequisite of realistic molecular dynamics simulations of bacterial and plant photoreaction centers. In this work, we compare two available sets of parameters for bacteriochlorophyll in extended 200 ns simulations of photoreaction centers from Rhodobacter Sphaeroides in the membrane environment. It is shown that the most popular and widely used set of parameters produces artifacts in cofactor positions and orientations. It is also shown that the hydration of cofactors may vary, by dramatically depending on the used force field. Some recommendations for the further force field development are made.

Keywords: bacterial photoreaction centers, Rhodobacter Sphaeroides, molecular dynamics, force field, cofactor hydration.
\end{abstract}

\section{Introduction}

Photoreaction centers (RC) from Rhodobacter Sphaeroides are well known model objects in the biophysics of photosynthesis, which are being studied for several decades $[1,2]$. The relative ease of experimental manipulations and the rich dynamic behavior of these molecules make them ideal objects for experimental and theoretical studies of the charge transfer phenomena and conformational changes, which accompany the initial photoexcitation [3-5].

Molecular Dynamics (MD) simulations could provide valuable insights into the dynamics of RCs on the atomic level. Particularly, they could detect conformational changes in the protein, which follow the initial charge separation induced by the photoexcitation. MD simulations are also very promising for clarifying the question of the cofactor hydration in RCs. Crystal structures of the RCs reveal only few tightly bound water molecules in vicinities of chromophores [6, 7], while the free volume of the internal cavity is large enough to accommodate much more solvent molecules. A surprisingly little attention was paid to the problem of hydration and water dynamics in the internal cavities of RCs in either experimental

(C) S. YESYLEVSKYY, N. BEREZETSKAYA,

M. OLENCHUK, 2016 or computational studies. Recent experimental works show that the pool of RC-bound water stabilizes the charge-separated state of RC [8] It is also shown that the dehydration inhibits the electron transfer reactions in RCs [9]. There is an evidence that even a single water molecule could change the charge separation rate significantly [10]. MD simulations are an ideal tool for the direct observation of the hydration dynamics in the internal cavities of RCs.

Despite the large number of experimental works, there are only few devoted to computational studies of RCs, because the modeling of their chromophores and cofactors appears to be nontrivial. RCs contain three major types of cofactors - bacteriochlorophyll (BCL), bacteriopheophytin (BPH), and quinone $(\mathrm{Q})$, which are involved in the electron transfer reaction under the photoexcitation. There are no parameters for these compounds in widely used empirical MD force fields. Due to the large number of atoms in these cofactors, their parametrization becomes tedious time-consuming task.

To our knowledge, there is only one dedicated set of parameters for all cofactors of the bacterial $\mathrm{RC}$ (BCL, BPH, and Q) developed to date by Ceccarelli et al. [11]. These parameters were derived from $a b$ initio quantum chemical calculations following the guidelines of the AMBER force field development

ISSN 2071-0194. Ukr. J. Phys. 2016. Vol. 61, No. 10 
[12]. These parameters will be referred as "Ceccarelli parameters" hereafter. Ceccarelli parameters are used as a basis for the parametrization of similar cofactors of the plant photosystem II [13]. They were used successfully in several MD studies of RCs [14, 15]. However, the length of MD trajectories did not exceed $10 \mathrm{~ns}$ in these works, and the applicability of used parameters for long MD simulations is still not known.

There is also an alternative set of parameters for chlorophyll A, which was developed by Roccatano et al. [16]. These parameters are compatible with the OPLS-AA force field [17]. Bonded parameters and charges are based on $a b$ initio quantum chemical calculations, while non-bonded interactions are finely tuned according the comparison with available experimental data such as rotational time constants of chlorophyll A in organic solvents. These parameters will be referred as "Roccatano parameters" hereafter. To our knowledge, the Roccatano parameters were never used in the simulations of plant or bacterial $\mathrm{RCs}$ to date.

In this work, we will perform a systematic comparison of Ceccarelli and Roccatano parameters in extensive ( $\sim 200 \mathrm{~ns})$ MD simulations of the dark-adapted RCs embedded into a model lipid bilayer. The stability of positions and mutual orientations of cofactors will be monitored. The hydration of chromophores and the dynamics of water accumulation in the internal cavity of $\mathrm{RC}$ will be studied.

\section{Materials and Methods}

All simulations were performed with the GROMACS 4.5.5 software [18] The crystal structure of a darkadapted RC (PDB code 1PCR) was used [6]. The RC was embedded into the pre-equilibrated 1,2-dioleoylsn-glycero-3-phosphocholine (DOPC) bilayer using the ProtSqueeze method [19]. The V-rescale temperature coupling algorithm was used. Water and the rest of the system were coupled to the separate heat bathes at $300 \mathrm{~K}$. The semiisotropic Berendsen pressure coupling with a relaxation constant of 5 ps and the reference pressure of 1 bar were used. The particle-mesh Ewald (PME) method [20] was used to compute long-range electrostatic interactions. The lengths of all bonds were constrained by the LINCS algorithm [21], while the bonds in water molecules were constrained, by using SETTLE [22]. The trajectories were saved each 8 ps. The AMBER03 force field

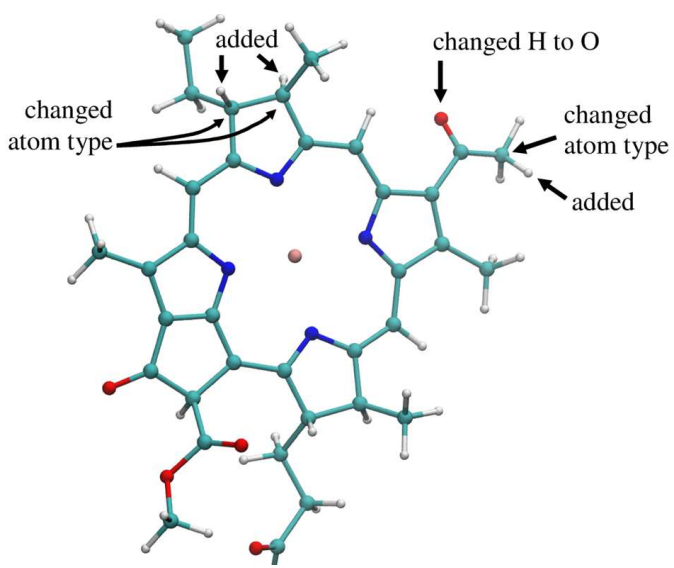

Fig. 1. Part of a BCL molecule with the atoms, which are added or modified upon the conversion from chlorophyll A

[23] was used for the protein and lipids. The TIP3P water model was used.

The Ceccarelli parameters of all cofactors were obtained from the authors in the format compatible with the ORAC [24] MD software and converted to the GROMACS format, by using the custom scripts.

The Roccatano parameters are available for chlorophyll $\mathrm{A}$ in the form compatible with the OPLAAA force field. Chlorophyll A and bacteriochlorophyll molecules are very similar and differ by only four atoms. The topology of chlorophyll A was converted to BCL in a naïve way by adding three missing hydrogen atoms and by changing one hydrogen to carbonyl oxygen (Fig. 1). The necessary bond, angle, and dihedral entries were added for new atoms with the parameters taken from existing chemical groups of the same type. The atom types of three carbon atoms, which change their hybridization state upon the transition to BCL, were changed accordingly. We did not change any charges of existing atoms, while the additional hydrogen atoms were assigned zero charges. This allows keeping the original parameters, which were validated against experimental data, as much as possible.

The non-bonded Roccatano parameters were used despite the difference of the functional form of combination rules used in the OPLS-AA and AMBER force fields. Our previous experience shows that such change of the combination rules is very unlikely to produce artifacts in production simulations.

The system was hydrated initially, by using a genbox program from the GROMACS suit. All water 


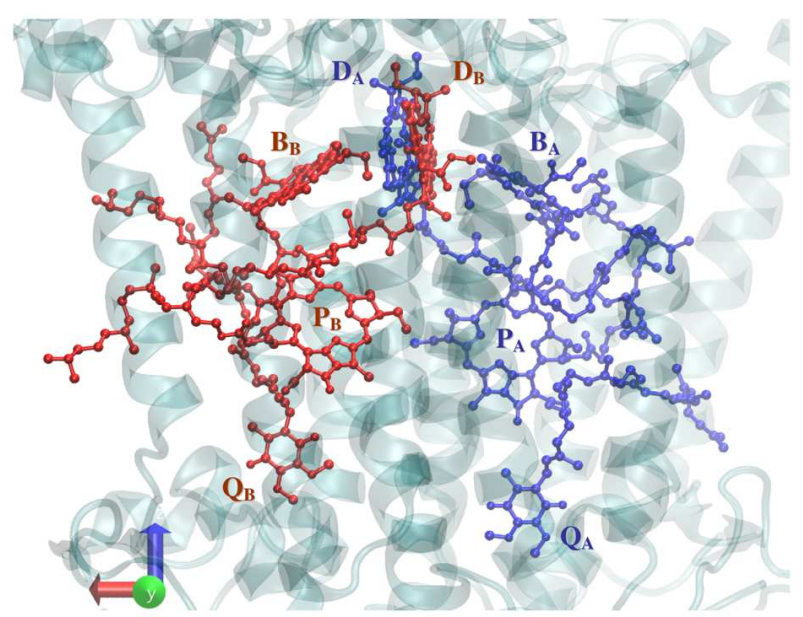

Fig. 2. Initial structure of RC. Individual cofactors are indicated. The protein is shown in the semitransparent cartoon representation

molecules from the hydrocarbon core of the bilayer and the cavity of $\mathrm{RC}$ were deleted. After that, the necessary number of counter-ions was added, and the energy of the system was minimized. The lipids and water molecules were equilibrated for $50 \mathrm{~ns}$, while the protein and all cofactors were frozen. Then two independent production simulations were performed with Ceccarelli and Roccatano parameters, respectively. Since there are no Roccatano parameters for $\mathrm{BPH}$ and Q cofactors, we were forced to use Ceccarelli parameters for them in both simulations. The lengths of simulations were 222 ns and 202 ns, respectively.

The analysis of trajectories was performed by a custom analysis plugin for the Pteros molecular modeling library [25]. The hydration of cofactors was estimated as the number of water molecules, which reside within $6 \AA$ from any atom of a particular cofactor.

The cofactors are named according to the original work [6]. The BCL molecules of the special pair are named $\mathrm{D}_{A}$ and $\mathrm{D}_{B}$; monomeric $\mathrm{BCL}$ molecules are referred as $\mathrm{B}_{A}$ and $\mathrm{B}_{B}$; $\mathrm{BPH}$ molecules are referred as $\mathrm{P}_{A}$ and $\mathrm{P}_{B}$, and the quinone molecules are called $\mathrm{Q}_{A}$ and $\mathrm{Q}_{B}$. An arrangement of cofactors in the initial system is shown in Fig. 2.

\section{Results and Discussion}

\subsection{Stability of the protein}

The structure of the RC protein remains remarkably rigid in both simulations. The root-means square de- viations of $C_{\alpha}$ atoms of the protein reach $0.25 \mathrm{~ns}$ at maximum and remain stable, by starting from $\sim 100$ ns of simulations (data not shown). The force field of BCL molecules does not influence the equilibrium structure of the protein.

\subsection{Positions and orientations of cofactors}

The positions and orientations of BCL molecules show the dramatic difference in the Ceccarelli and Roccatano force fields. Figure 3 shows the evolutions of the angle between the porphyrin rings of $D_{A}$ and $D_{B}$ molecules of the special pair and the distance between their $\mathrm{Mg}$ atoms. It is clearly seen that the angle between the porphyrin rings fluctuates significantly from $5^{\circ}$ to $33^{\circ}$ with Ceccarelli parameters. Roccatano parameters lead to much smaller fluctuations of the angle from $10^{\circ}$ to $22^{\circ}$. Despite this difference, the average orientation of the BCL molecules of a special pair remains consistent with the crystal structure in both simulations. The distance between $D_{A}$ and $D_{B}$ molecules increases to 0.95-1.0 $\mathrm{nm}$ in the case of Ceccarelli parameters, which is significantly larger than a distance of $0.76 \mathrm{~nm}$ observed in the crystal structure. In contrast, Roccatano parameters lead to only a marginal increase of the distance to $0.8-0.85 \mathrm{~nm}$. In general, the arrangement of a special pair is much more stable and closer to the crystal structure with Roccatano parameters.

Even larger differences are observed for $B_{A}$ and $B_{B}$ molecules. In the crystal structure, the $\mathrm{A}$ and $\mathrm{B}$ branches of cofactors are quasisymmetric. The positions and orientations of the porphyrin rings of $\mathrm{BCL}$ and $\mathrm{BPH}$ molecules are almost symmetric in relation to the special pair in the crystal structure. Figure 4 shows the evolution of the orientations of $B_{A}$ and $B_{B}$ porphyrin rings in relation to the special pair. In is clearly seen that the corresponding angles are $\sim 80^{\circ}$ and $\sim 100^{\circ}$ in the initial structure, which is almost perfectly symmetric in respect to $90^{\circ}$. In the case of Ceccarelli parameters, this symmetry is broken dramatically from the beginning of the simulation. The angle for $B_{A}$ molecules decreases rapidly to $90^{\circ}$ and fluctuates around this value till the end of the simulation. In contrast, the porphyrin ring of a $B_{B}$ molecule rotates by a large angle (more than $60^{\circ}$ ) in less than $20 \mathrm{~ns}$ and reaches the angle of $20^{\circ}$. Its orientation changes gradually during the 

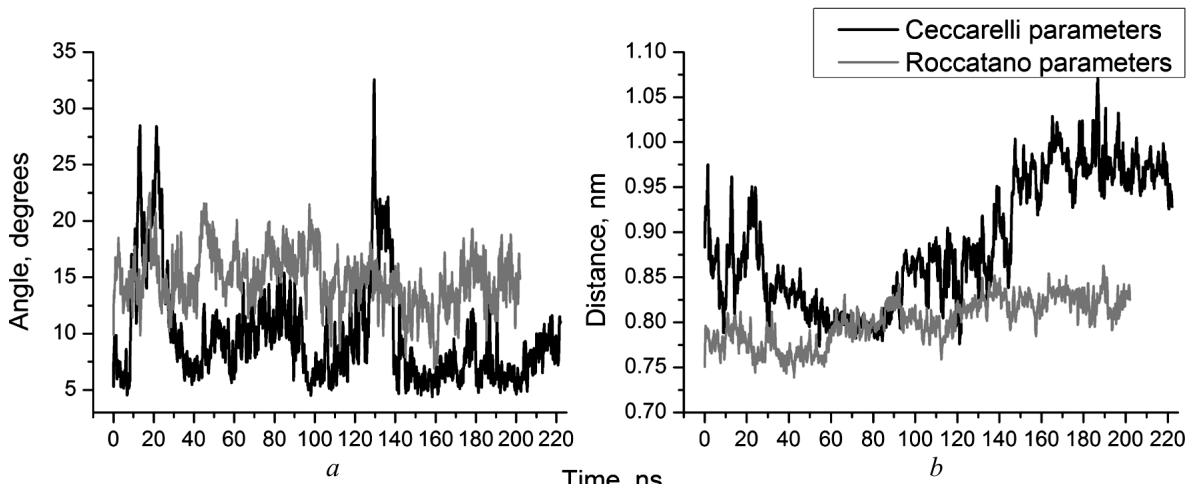

Fig. 3. (Angle between the porphyrin rings of BCL molecules in a special pair $(a)$. The distance between $\mathrm{Mg}$ atoms of the BCL molecules in a special pair $b$ )

simulation and equilibrates at the value of $\sim 55^{\circ}$ after $150 \mathrm{~ns}$.

In contrast, the orientations of $B_{A}$ and $B_{B}$ rings do not change significantly in the case of Roccatano parameters. The arrangement of the rings remains quasisymmetric and does not change by more than $10^{\circ}$ during the simulation.

\subsection{Hydration of cofactors}

The hydration of a cofactor changes during the simulation due to the spontaneous accumulation of water molecules in the cavity of RC. Figure 5, a shows the accumulation of water molecules around the special pair. It is evident that, in the case of Ceccarelli parameters, the equilibrium hydration is reached after $\sim 120 \mathrm{~ns}$ of the simulation. More than 70 water molecules are accumulated around the special pair, while initially only 5 water molecules were present in the cavity. In the case of Roccatano parameters, only $15-20$ water molecules hydrate the special pair in equilibrium.

The most striking difference in the hydrations is observed for $B_{A}$ and $B_{B}$ BCL molecules (Fig. 5, b). In the case of Ceccarelli parameters, both cofactors are hydrated by 20-35 water molecules at the end of simulations. In contrast, only $2-3$ water molecules hydrate these cofactors in the case of Roccatano parameters, which means that they are located in the almost water-free environment.

A similar trend is also observed for BPH molecules $P_{A}$ and $P_{B}$ (Fig. 5,c): their hydration is much higher with Ceccarelli parameters. The hydration of quinone molecules (Fig. 5, d) is almost the same in both

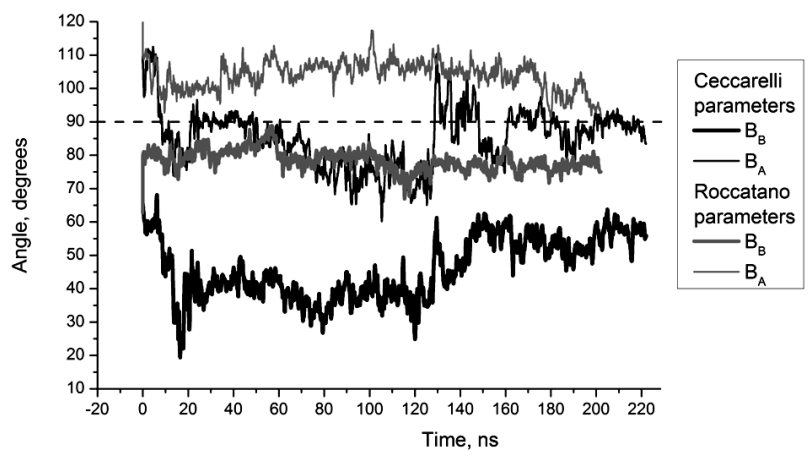

Fig. 4. Angles between the porphyrin rings of monomeric BCL molecules $\mathrm{B}_{A}$ and $\mathrm{B}_{B}$ and the average normal of the special pair

simulations. However, the number of water molecules around quinones fluctuates more in the case of Ceccarelli parameters.

\subsection{Quality of the force fields}

The quality of the force field parameters of such complex molecules as bacteriochlorophyll, bacteriopheophytin, and quinone is the major concern in extended MD simulations of RCs. These cofactors are located in a very complex and highly heterogeneous environment. As a result, the correct parametrization of cofactors becomes a very challenging task.

Numerous experimental and simulation studies show that positions and orientations of porphyrin rings of $\mathrm{BCL}$ and $\mathrm{BPH}$ cofactors should be rather stable in MD simulations. Our simulations show that the most complete and widely used set of Ceccarelli parameters behaves inadequately in long $200 \mathrm{~ns}$ MD simulations in this respect. The special pair of 


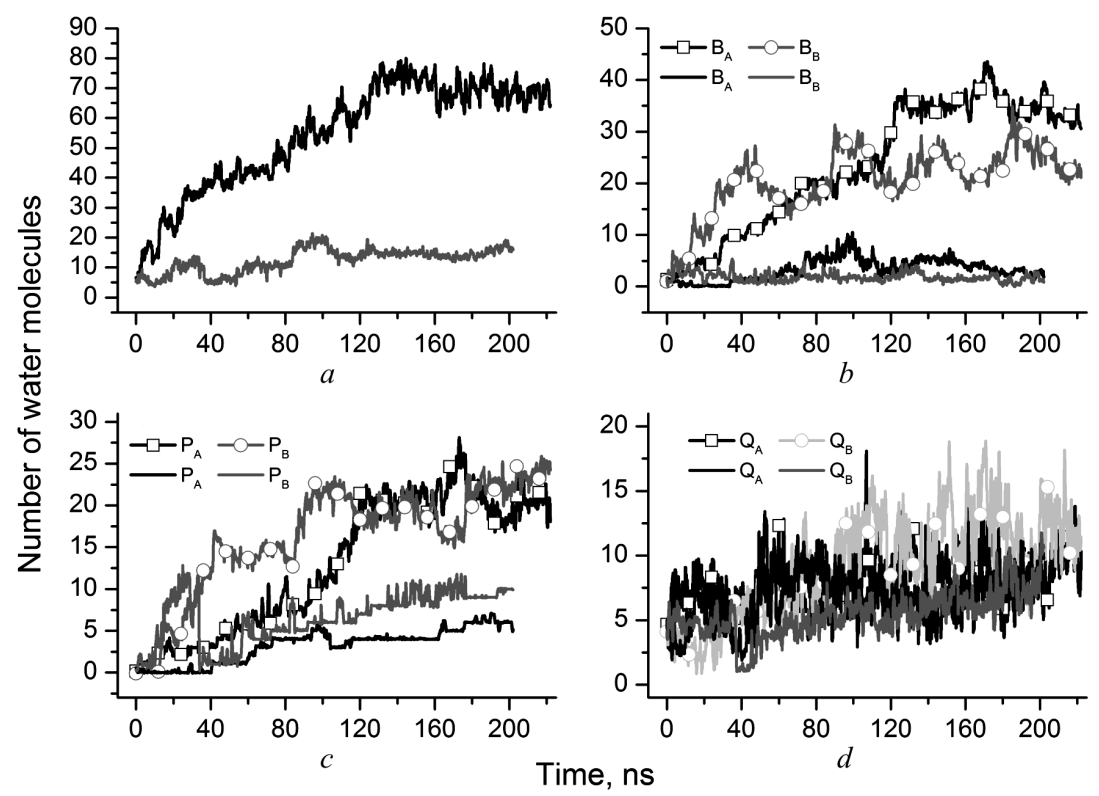

Fig. 5. Number of water molecules within $0.6 \mathrm{~nm}$ of different cofactors as a function of the simulation time $(a)$. The special pairs of $\mathrm{B}_{A}$ and $\mathrm{B}_{B}$ molecules $(b), \mathrm{P}_{A}$ and $\mathrm{P}_{B}$ molecules $(c)$, and $\mathrm{Q}_{A}$ and $\mathrm{Q}_{B}$ molecules $(d)$. The curves for Ceccarelli and Roccatano parameters are shown in black and in gray

BCL molecules becomes rather unstable with the distance between $D_{A}$ and $D_{B}$ molecules increasing to $0.95-1.0 \mathrm{~nm}$ from $0.76 \mathrm{~nm}$ observed in the crystal structure. The orientations of $B_{A}$ and $B_{B}$ molecules become strikingly asymmetric, with the $B_{B}$ molecule rotating by more than $60^{\circ}$ during the simulation. Such large change of the orientation is very unlikely to be realistic and suggests a problem in the force field. In contrast, the Roccatano parameters are free from these artifacts. The special pair demonstrates a remarkable stability with these parameters. The orientations of $B_{A}$ and $B_{B}$ molecules also fluctuate within $10^{\circ}$ from their values in the crystal structure.

The parameters used in this study lead to very divergent results for the cofactor hydration. In the case of Ceccarelli parameters, the protein cavity becomes fully hydrated in less than 150 ns. More than 70 water molecules are found in a vicinity of the special pair. The $B_{A}$ and $B_{B}$ BCL molecules are also hydrated significantly by $20-35$ water molecules. In contrast, the Roccatano parameters lead to much smaller hydration numbers. The special pair is hydrated by only $10-15$ water molecules with these parameters, while $B_{A}$ and $B_{B}$ molecules are not hy- drated at all (only 2-5 molecules are found within $0.6 \mathrm{~nm}$ from them).

Due to the lack of experimental data, it is not possible to conclude, which force field produces more realistic hydration numbers. We can speculate, however, that the hydration observed with Ceccarelli parameters is excessive and caused by an inadequately large rotation of the hydrophobic porphyrine rings.

This work clearly shows the critical importance of the adequate choice of cofactor parameters in extended MD simulations of RCs. Although the further work on the parameters of cofactors is needed, it is possible to conclude that the Roccatano parameters can serve as a solid basis for their development. According to our results, the popular Ceccarelli parameters should be used with great caution because of possible severe artifacts with orientations and positions of cofactors.

\section{Conclusions}

In this work, we have performed the systematic comparison of two available sets of parameters for bacteriochlorophyll $[11,16]$ in extended $200 \mathrm{~ns}$ simulations of photoreaction centers from Rhodobacter Sphaeroides 
in the membrane environment. It is shown that the most popular and widely used set of parameters from Ceccarelli et al. [11] produces artifacts in the structure of the special pair and orientations of $B_{A}$ and $B_{B}$ cofactors. It is also shown that the hydration of cofactors may vary dramatically, by depending on the used force field. It is shown that an adequate choice of cofactor parameters is of critical importance for extended MD simulations of RCs. It is possible to conclude that the parameters from Roccatano et al. [16] can serve as a solid basis for the further determination of cofactor parameters. The popular Ceccarelli parameters should be used with great caution because of possible severe artifacts with orientations and positions of cofactors.

1. R.K. Clayton, Primary processes in bacterial photosynthesis, Ann. Rev. Biophys. Bioengin. 2, No. 1, 131 (1973) [DOI: 10.1146/annurev.bb.02.060173.001023].

2. W.W. Parson and R.J. Cogdell, The primary photochemical reaction of bacterial photosynthesis, Biochem. Biophys. Acta 416, No. 1, 105 (1975).

3. Y.M. Barabash, N.M. Berezetskaya, L.N. Christophorov, A.O.Goushcha, and V.N. Kharkyanen, Effects of structural memory in protein reactions, J. Chem. Phys. 116, No. 10, 4339 (2002) [DOI: 10.1063/1.1447906].

4. A.O. Goushcha, A.J. Manzo, G.W. Scott, L.N. Christophorov, P.P. Knox, Y.M. Barabash, M.T. Kapoustina, N.M. Berezetska, and V.N. Kharkyanen, Self-regulation phenomena applied to bacterial reaction centers: 2 . Nonequilibrium adiabatic potential: Dark and light conformations revisited, Biophys. J. 84, No. 2, 1146 (2003) [DOI: 10.1016/S0006-3495(03)74930-3].

5. A.O. Goushcha, V.N. Kharkyanen, G.W. Scott, and A.R. Holzwarth, Self-regulation phenomena in bacterial reaction centers. I. General theory, Biophys. J. 79, No. 3, 1237 (2000) [DOI: 10.1016/S0006-3495(00)76378-8].

6. U. Ermler, G. Fritzsch, S.K. Buchanan, and H. Michel, Structure of the photosynthetic reaction centre from Rhodobacter sphaeroides at $2.65 \AA$ resolution: cofactors and protein-cofactor interactions, Structure 2, No. 10, 925 (1994) [DOI: 10.1016/S0969-2126(94)00094-8].

7. G. Katona, A. Snijder, P. Gourdon, U. Andreasson, O. Hansson, L.-E. Andreasson, and R. Neutze, Conformational regulation of charge recombination reactions in a photosynthetic bacterial reaction center, Nat. Struct. Mol. Biol. 12, N 7, 630 (2005) [DOI: 10.1038/nsmb948].

8. M. Malferrari, F. Francia, and G. Venturoli, Coupling between electron transfer and protein-solvent dynamics: FTIR and laser-flash spectroscopy studies in photosynthetic reaction center films at different hydration levels, J. Phys. Chem. B 115, No. 49, 14732 (2011) [DOI: 10.1021/jp2057767].

ISSN 2071-0194. Ukr. J. Phys. 2016. Vol. 61, No. 10
9. S.K. Chamorovsky, P.M. Krasil'nikov, and P.P. Knox, Effect of isotope substitution and controlled dehydration on the photoinduced electron transport reactions of quinone acceptors and multiheme cytochrome $\mathrm{c}$ in bacterial photosynthetic reaction center. Biokhim. 67, No. 11, 1298 (2002) [DOI: 10.1023/A:102131792535].

10. J.A. Potter, P.K. Fyfe, D. Frolov, M.C. Wakeham, R. van Grondelle, B. Robert, and M.R. Jones, Strong effects of an individual water molecule on the rate of light-driven charge separation in the Rhodobacter sphaeroides reaction center, J. Biol. Chem. 280, No. 29, 27155 (2005) [DOI: 10.1074/jbc.M501961200].

11. M. Ceccarelli, P. Procacci, and M. Marchi, An ab initio force field for the cofactors of bacterial photosynthesis, J. Computat. Chem. 24, No. 2, 129 (2003) [DOI: 10.1002/jcc.10198].

12. W.D. Cornell, P. Cieplak, C.I. Bayly, I.R. Gould, K.M. Merz, D.M. Ferguson, D.C. Spellmeyer, T. Fox, J.W. Caldwell, and P.A. Kollman, A second generation force field for the simulation of proteins, nucleic acids, and organic molecules, J. Am. Chem. Soc. 117, No. 19, 5179 (1995) [DOI: 10.1021/ja00124a002].

13. L. Zhang, D.-A. Silva, Y. Yan, X. Huang, Force field development for cofactors in the photosystem II, J. Computat. Chem. 33, No. 25, 1969 (2012) [DOI: 10.1002/jcc.23016].

14. M. Ceccarelli and M. Marchi, Simulation and modeling of the Rhodobacter sphaeroides bacterial reaction center: Structure and interactions, J. Phys. Chem. B 107, No. 6, 1423 (2003) [DOI: 10.1021/jp0270001].

15. S. Vasil'ev and D. Bruce, A protein dynamics study of photosystem II: The effects of protein conformation on reaction center function, Biophys. J. 90, No. 9, 3062 (2006) [DOI: 10.1529/biophysj.105.076075].

16. K. Karki and D. Roccatano, Molecular dynamics simulation study of chlorophyll a in different organic solvents, J. Chem. Theory Comput. 7, No. 4, 1131 (2011) [DOI: $10.1021 / \operatorname{ct} 100462]$.

17. W.L. Jorgensen, D.S. Maxwell, and J. Tirado-Rives, Development and testing of the OPLS all-atom force field on conformational energetics and properties of organic liquids, J. Am. Chem. Soc. 118, No. 45, 11225 (1996) [DOI: $10.1021 /$ ja9621760].

18. B. Hess, C. Kutzner, D. van der Spoel, and E. Lindahl, GROMACS 4: Algorithms for highly efficient, load-balanced, and scalable molecular simulation, J. Chem. Theory Comput. 4, No. 3, 435 (2008) [DOI: 10.1021/ct700301q].

19. S.O. Yesylevskyy, ProtSqueeze: Simple and effective automated tool for setting up membrane protein simulations, J. Chem. Inf. Model. 47, 1986 (2007) [DOI: 10.1021/ci600553y].

20. U. Essmann, L. Perera, M.L. Berkowitz, T. Darden, H. Lee, and L.G. Pedersen, A smooth particle mesh Ewald method, J. Chem. Phys. 103, No. 19, 8577 (1995) [DOI: 10.1063/1.470117].

21. B. Hess, P-LINCS: A parallel linear constraint solver for molecular simulation, J. Chem. Theory Comput. 4, No. 1, 116 (2008) [DOI: 10.1021/ct700200b]. 
22. S. Miyamoto and P.A. Kollman, Settle: An analytical version of the SHAKE and RATTLE algorithm for rigid water models, J. Comput. Chem. 13, No. 8, 952 (1992) [DOI: $10.1002 /$ jcc.540130805].

23. Y. Duan, C. Wu, S. Chowdhury, M.C. Lee, G. Xiong, W. Zhang, R. Yang, P. Cieplak, R. Luo, T. Lee, J. Caldwell, J. Wang, and P. Kollman, A point-charge force field for molecular mechanics simulations of proteins based on condensed-phase quantum mechanical calculations, J. Comput. Chem. 24, No. 16, 1999 (2003) [DOI: 10.1002/jcc.10349].

24. S. Marsili, G.F. Signorini, R. Chelli, M. Marchi, and P. Procacci, ORAC: A molecular dynamics simulation program to explore free energy surfaces in biomolecular systems at the atomistic level, J. Comput. Chem. 31, No. 5, 1106 (2010) [DOI: 10.1002/jcc.21388].

25. S.O. Yesylevskyy, Pteros: Fast and easy to use open-source $\mathrm{C}++$ library for molecular analysis, J. Comput. Chem. 33, No. 19, 1632 (2012) [DOI: 10.1002/jcc.2298].

Received 05.04.16
С. Єсилевсъкий, Н. Березецъка, М. Оленчук

ПОРІВНЯННЯ ЕМПІРИЧНИХ

СИЛОВИХ ПОЛІВ ДЛЯ БАКТЕРІОХЛОРОФІЛУ:

ВПЛИВ НА ГІДРАТАЦІЮ ТА ПОВІЛЬНУ ДИНАМІКУ

БАКТЕРІАЛЬНИХ ФОТОСИНТЕТИЧНИХ ЦЕНТРІВ

$\mathrm{P}$ е $з$ ю м е

Вибір адекватного силового поля для фотосинтетичних кофакторів є основною передумовою проведення реалістичного моделювання бактеріальних та рослинних фотосинтетичних центрів. В цій роботі порівняно два набори параметрів для бактеріохлорофілу у симуляціях методом молекулярної динаміки довжиною 200 нс фотосинтетичного центру бактерії Rhodobacter Sphaeroides у мембранному оточенні. Показано, що найбільш популярний набір параметрів продукує артифакти у положеннях та орієнтаціях кофакторів. Також показано, що гідратація кофакторів може сильно змінюватися в залежності від використаного силового поля. Надано рекомендації щодо подальшої розробки силових полів для фотосинтетичних кофакторів. 